\title{
Effects of Pulverized Fuel Ash and Condensed Silica Fume on Heat Generation of Curing Concrete
}

\author{
J. J. Chen ${ }^{1, ~ *, ~ H . ~ N . ~ C h e n ~}{ }^{2}$, L. G. Li $^{3}$ \\ ${ }^{1}$ Department of Civil Engineering, Foshan University, Foshan, China \\ ${ }^{2}$ Space Structures Research Center, Guizhou University, Guiyang, China \\ ${ }^{3}$ School of Civil and Transportation Engineering, Guangdong University of Technology, Guangzhou, China
}

Email address:

chenjiajian@fosu.edu.cn (J. J. Chen), ligu123@msn.com (L. G. Li)

${ }^{*}$ Corresponding author

\section{To cite this article:}

J. J. Chen, H. N. Chen, L. G. Li. Effects of Pulverized Fuel Ash and Condensed Silica Fume on Heat Generation of Curing Concrete. International Journal of Materials Science and Applications. Vol. 5, No. 6, 2016, pp. 271-276. doi: 10.11648/j.ijmsa.20160506.16

Received: September 20, 2016; Accepted: November 2, 2016; Published: November 5, 2016

\begin{abstract}
The heat generated during the curing period of concrete may results in early thermal cracking. To avoid or at least alleviate this early thermal cracking problem, replacing part of cement by cementitious materials should be an effective method. Herein, it is proposed to add PFA or CSF as cement replacement to lower the cement content and heat generated from the hydration of cement. To study the effectiveness of adding PFA or CSF in reducing the heat generation of curing concrete, a series of concrete mixes with water/cement ratios ranging from 0.24 to 0.40 and different amounts of PFA or CSF added were tested for their heat generation. The results illustrated that the addition of PFA or CSF as cement replacement could effectively reduce the adiabatic temperature rise and heat generation of curing concrete, while the addition of CSF is much more effectively than addition of PFA in reducing heat generation at the same strength.
\end{abstract}

Keywords: Condensed Silica Fume, Temperature Rise, Pulverized Fuel Ash

\section{Introduction}

Hydration of cement and pozzolanic reaction of cementitious materials would generate heat inside the concrete mixture during the curing period. With the heat thus accumulated, the temperature of concrete would rise. Afterwards, the temperature of concrete would gradually drop to the ambient environmental temperature and lead to contraction of the concrete structure. If there exists any restraint against the thermal movements so caused, tensile strains would occur and is likely to lead to early thermal cracking.

The thermal cracking thus produced would adversely affect the aesthetics, water-tightness, structural integrity and durability of the concrete structure. To avoid or at least alleviate this early thermal cracking problem, reducing the heat generation of the concrete should be the first consideration as other means of temperature control, such as lowering the placing temperature, internal cooling and external insulation, are rather cumbersome.
As the pozzolanic reaction of cementitious materials generates less heat than the hydration of cement, replacing part of cement by cementitious materials should be an effective method to reduce the heat generation. Following this strategy, cementitious materials such as pulverized fuel ash (PFA), ground granulated blastfurnace slag (GGBS), condensed silica fume (CSF) and metakaolin (MK) can be used. Since PFA is relatively economical compared to other candidates, and CSF is able to increase the strength at the same time, PFA and CSF should be good choices among the cementitious materials [1-10].

Early in 1983, with the use of isothermal calorimetry, Meland [11] found that CSF replacement up to $20 \%$ could significantly decrease the heat generation. Lessard et al. [12] showed that replacing $35 \%$ of cement by GGBS and $15 \%$ of cement by CSF could lower the heat of hydration by $30 \%$ while keeping the same 28-day strength. Kurdowski and Nocun-Wczelik [13] pointed out that the hydration of cement 
with high alite content would benefit from CSF and as a result the presence of CSF would intensify the initial heat evolution of alite. In 1984, Kumar and Roy [14] observed by thermogravimetry that depending on the particular cement and the amount of CSF added, CSF replacement could reduce the heat generation by $15 \%$ to $30 \%$. In 1985 , Huang and Feldman [15] concluded that the total heat generation would decrease as CSF is added to replace cement.

In 1994, Ma et al. [16] showed by isothermal calorimetry that the heat generation of CSF cement is dependent on the hydration temperature and that a $7.5 \% \mathrm{CSF}$ cement would generate more heat than pure cement at 10 to $25^{\circ} \mathrm{C}$ but less heat than pure cement at $55^{\circ} \mathrm{C}$. In 1995, Sanchez de Rojas and Frias [17] showed that $10 \%$ CSF replacement would increase the heat generation while $30 \%$ CSF replacement would decrease the heat generation. However, in 1997, Alshamsi [18] got results expressing that $10 \%$ CSF replacement would slightly decrease the heat generation. In 1998, Bentz et al. [19] expressed that CSF would probably reduce the degree of cement hydration because some of the water is incorporated into the pozzolanic reaction products and thus unavailable for cement hydration.

In 2002, Langan et al. [20] showed that PFA replacement would slow down the rate of heat generation and such retardation effect is more significant at a higher $\mathrm{W} / \mathrm{CM}$ ratio. In 2005, Mostafa and Brown [21] found that 10\% CSF replacement would slightly increase while $20 \%$ to $30 \% \mathrm{CSF}$ replacement would decrease the 45 -hour heat generation. In 2008, Snelson et al. [10] showed out that the decrease in cement content caused by PFA replacement would increase the water to cement ratio and degree of hydration, thereby compensating partly the reduction in heat generation due to the decrease in cement content. $\mathrm{Ng}$ et al. [22] conducted semi-adiabatic curing tests of CSF concretes with heat loss compensation applied and got the results that at a W/CM ratio of $0.40,5 \%$ to $15 \% \mathrm{CSF}$ replacement would decrease the heat generation by a percentage roughly equal to the percentage of cement replaced by CSF. In 2009, Kadri and Duval [23] measured the heat generation of concretes with a semi-adiabatic method up to 10 days and obtained the results that at all $\mathrm{W} / \mathrm{CM}$ ratios, $10 \% \mathrm{CSF}$ replacement would increase while $20 \%$ or $30 \%$ CSF replacement would decrease the heat generation.

As both hydration of cement and pozzolanic reaction of PFA and CSF require water [24], the water content should play a certain role in their degrees of chemical reactions. Hence, when studying the effects of PFA and CSF, the W/CM ratio should be taken into consideration. However, there has been only limited research. On this issue, Langan et al. [20] showed that the effects of CSF vary with the W/CM ratio in such as a way that at high $\mathrm{W} / \mathrm{CM}$ ratio, the CSF has little effect on the rate of cement hydration while at low W/CM ratio, the CSF would slow down the rate of cement hydration. This is probably because at lower W/CM ratio, the amount of water available for cement hydration is smaller and therefore the taking up of water by the pozzolanic reaction of CSF is more significant. Kadri and Duval [23] expressed that for concretes with $0 \%$ to $30 \%$ CSF replacement, both the rate and amount of heat generation per cementitious materials content are lower at lower $\mathrm{W} / \mathrm{CM}$ ratio.

From the above literature review, the use of PFA or CSF as cement replacement would allow the cement to be decreased to reduce the heat generation. This use of PFA or CSF could keep the W/CM ratio constant so that there will be no significant adverse effect or even beneficial effect on the strength, and therefore effectively reduce heat generation on the strength basis, as demonstrated in this study.

\section{Materials}

An ordinary Portland cement (OPC) of strength class 52.5N complying with British Standard BS 12: 1996 (equivalent to ASTM Type I), a low calcium pulverized fuel ash (PFA) complying with British Standard BS 3892: Part 1: 1997 (equivalent to ASTM Class F) and a condensed silica fume (CSF) complying with ASTM C 1240-05 were used as the cementitious materials for all the concrete mixes. Both the coarse and fine aggregates were obtained from crushed granite rock. The coarse aggregate has a maximum size of 20 $\mathrm{mm}$. Its specific gravity and water absorption were measured to be 2.61 and $1.01 \%$, respectively. The fine aggregate has a maximum size of $5 \mathrm{~mm}$. Its specific gravity, water absorption and fineness modulus were measured to be $2.52,1.89 \%$ and 2.68 , respectively. Sieve analysis verified that the grading curves of the coarse and fine aggregates were within the allowable limits stipulated in British Standard BS 882: 1992.

\section{Concrete Mixes and Specimens}

In this study, 5 concrete mixes without any PFA and CSF added, 10 concrete mixes with PFA added and 10 concrete mixes with CSF added were produced for testing. Their $\mathrm{W} / \mathrm{CM}$ ratio was varied from 0.24 to 0.40 in increments of 0.04 . PFA replacement content was varied between $20 \%$ and $40 \%$ by weight of total cementitious materials and CSF replacement content was varied among $5 \%$ and $10 \%$ by weight of total cementitious materials so as to study the combined effects of $\mathrm{W} / \mathrm{CM}$ ratio, PFA replacement content and CSF replacement content. These chosen ranges of W/CM ratio as well as PFA and CSF replacement contents are similar to those commonly adopted for the production of normal- and high-strength concretes.

The fine to total aggregate ratio and paste volume to concrete volume ratio of every concrete mix were fixed at 0.40 and 0.34 , respectively. As in usual practice, especially for the production of concrete mixes with relatively low $\mathrm{W} / \mathrm{CM}$ ratios, a ploycarboxylate ether based superplasticizer (SP) was added to each concrete mix to achieve an adequate workability for proper placing and compaction.

From each concrete mix, one $0.4 \mathrm{~m}$ cube specimen was cast in the plastic bag inside the phenolic polymer boards of the mold for temperature rise measurement. After casting, the concrete specimen was sealed and left undisturbed for at least 7 days, during which the temperature inside the concrete and 
the ambient temperature were continuously measured by an automatic data-logger. Three $0.15 \mathrm{~m}$ cube specimens were cast as well for cube strength measurement. The concrete cubes were demolded at 24 hours after casting and then put into a lime-saturated water curing tank controlled at a temperature of $27 \pm 2{ }^{\circ} \mathrm{C}$ until the age of 28 days for cube compression test.

\section{Measurement of Heat Generation}

To measure the adiabatic temperature rise of the concrete specimens, a semi-adiabatic curing test method developed previously $[22,25]$ was followed in this study. The test set-up consists of a mould provided with both internal and external heat insulation. The mould itself is a cubic box made of 18 $\mathrm{mm}$ thick plywood. Inside the plywood box, a $150 \mathrm{~mm}$ thick phenolic polymer board is affixed onto each of the six faces to serve as internal insulation. The space surrounded by the internal insulation is where the $0.40 \mathrm{~m}$ concrete cube specimen is to be cast. As the phenolic polymer has lower specific heat capacity and heat conductivity than the plywood, this arrangement would minimize the amount of heat absorbed by the mould. To minimize heat conduction to the ground, the plywood box is lifted off the ground by wooden spacers. Furthermore, to avoid leakage, the concrete is cast inside a plastic bag, which is sealed after casting. On the outside, an external shell, made of $50 \mathrm{~mm}$ thick polystyrene foam boards, is mounted. Between the external shell and the plywood box, there is a $50 \mathrm{~mm}$ thick air gap. The external shell and the air gap together serve as external insulation of the mould. During the entire testing period, the ambient temperature around the test set-up is regulated within 22 to $24^{\circ} \mathrm{C}$ by air-conditioning.

The temperature of the concrete specimen is measured using thermocouples mounted at four locations, namely, the center of mass, center of one face, mid-point of an edge and one corner. Four additional thermocouples are attached at the outside faces of the external shell to measure the ambient temperature. All thermocouples are type $\mathrm{K}$ thermocouples. They are connected to a data-logger, which automatically records the temperature readings of the thermocouples at 5-minute intervals.

Basically, this test method measures the temperature of the concrete specimen up to the age of 7 days, estimates the heat loss of the concrete specimen from the temperature drop after the age of 6 days when the heat generation has become insignificant, and then compensates for the heat loss to determine the adiabatic temperature rise of the concrete. The formulae for heat loss compensation are given in the following.

Let $T_{V}$ be the volumetric mean temperature of the concrete, TS be the surface mean temperature of the concrete and $T_{A}$ be the ambient temperature. The rate of heat loss of the concrete should be proportional to $\left(T_{S}-T_{A}\right)$. After a certain period of time, when the heat generation of the concrete has become insignificant, the rate of heat loss, expressed in terms of the rate of temperature drop, is governed by:

$$
\frac{\partial T_{V}}{\partial t}=-\lambda\left(T_{S}-T_{A}\right)
$$

in which $\lambda$ is the heat loss characteristic of the test set-up and $t$ is the time after mixing. The actual value of $\lambda$ may be estimated from the measured temperature-time curve of the concrete when the heat generation has become insignificant (say, after 6 days). Having estimated the value of $\lambda$, the adiabatic temperature rise of the concrete TG may be obtained as:

$$
T_{G}=\left(T_{V}-T_{P}\right)+\lambda \int_{0}^{t}\left(T_{S}-T_{A}\right) d t
$$

where $T_{P}$ is the placing temperature of the concrete. The volumetric mean temperature $T_{V}$ and surface mean temperature $\mathrm{T}_{\mathrm{S}}$ can be evaluated from the readings of the four thermocouples mounted at the center of mass, center of one face, mid-point of an edge and one corner. Using the values of $T_{V}$ and $T_{S}$ so evaluated and performing numerical integration for Equation (2), the adiabatic temperature rise at any time $t$ can be determined from the semi-adiabatic curing test results.

\section{Experimental Results}

\subsection{Adiabatic Temperature Rise}

In the semi-adiabatic test, the placing temperature $T_{P}$ and volumetric mean temperature $T_{V}$ of each concrete specimen during the curing test were determined and the temperature rise of the concrete specimen at any time $t$ was then evaluated as $T_{V}-T_{P}$. The temperature rises-time curves so obtained reveal that generally the temperature of the concrete started to rise at an age of a few hours and reached a certain peak value at an age of within 16 to 50 hours. After reaching the peak, due to heat loss arising from imperfect heat insulation being larger than heat generation, the temperature of the concrete dropped. From these results, the measured temperature rise was taken as the maximum value of $\left(T_{V}-T_{P}\right)_{\max }$. To account for the effect of heat loss, heat loss compensation was applied to each concrete specimen as per the method described previously. Comparing the measured temperature rise-time curves before heat loss compensation with the adiabatic temperature rise-time curves after heat loss compensation, it is evident that the maximum temperature rise of each concrete mix would become significantly higher after heat loss compensation.

The variations of the adiabatic temperature rise with the W/CM ratio at different PFA and CSF replacement contents are plotted in Fig. 1. This figure reveals that at a W/CM content between 0.24 to 0.40 (common W/CM ratio range for normal- and high-strength concretes.), the adiabatic temperature rise decreased significantly as the increase in PFA replacement content or CSF replacement content. Such decrease in adiabatic temperature rise indicates that during the first few days, the heat generated from the pozzolanic reaction of the PFA or CSF added was less than the heat 
generated from the hydration of the cement replaced. When interpreting these results, it should be borne in mind that the change of adiabatic temperature rise with increasing W/CM ratio was the net effect of the increases in degree of hydration and degree of pozzolanic reaction, decrease in cementitious materials content and slight increase in specific heat capacity.

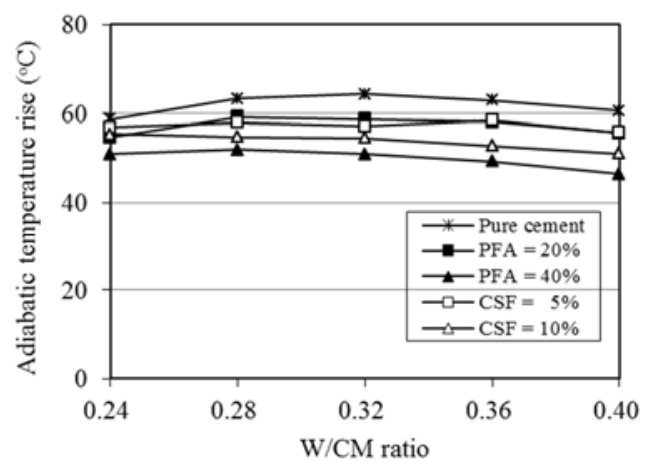

Figure 1. Results of adiabatic temperature rise.

\subsection{Total Heat Generation}

To calculate the amount of total heat generation for each concrete mix, the adiabatic temperature rise was multiplied with the specific heat capacity. It is noticed that the specific heat capacity of concrete varies during the early age. De Schutter and Taerwe [26] found that the specific heat capacity of curing concrete might decrease by $20 \%$ during hardening due to gradual reduction of the water content, which has the highest specific heat capacity. Van Breugel [27] suggested that the specific heat capacity of curing concrete should be a linearly decreasing function with the degree of hydration. On the other hand, De Larrard [28] pointed out that the specific heat capacity could increase by $10 \%$ due to temperature rise. Balancing these two opposite effects, the net change of specific heat capacity during curing should be small. Based on this argument, De Larrard suggested that the specific heat capacity of curing concrete may be assumed to be constant and taken simply as that of the fresh concrete. Following his suggestion, the specific heat capacity of curing concrete may be calculated as the sum of those of the constituents. Assuming that the specific heat capacities of water, cement, PFA, CSF and aggregate to be 4.19, 0.86, 0.73, 0.76 and $0.82 \mathrm{~kJ} / \mathrm{kg} /{ }^{\circ} \mathrm{C}$, respectively, as given in the references by De Schutter and Taerwe [26], Krishnaiah and Singh [29], and Holman [30] or calculated based on the chemical composition of the CSF and the respective thermal properties given by Lide [31], the specific heat capacity of curing concrete $\psi$ can be calculated as:

$$
\psi=4.19 W+0.86 O+0.73 P+0.76 C+0.82 A
$$

where $\psi$ is in $\mathrm{kJ} / \mathrm{m} 3 /{ }^{\circ} \mathrm{C}$, and $\mathrm{W}, \mathrm{O}, \mathrm{P}, \mathrm{C}$ and $\mathrm{A}$ are the water, $\mathrm{OPC}, \mathrm{PFA}, \mathrm{CSF}$ and aggregate contents, respectively, in $\mathrm{kg} / \mathrm{m}^{3}$. It is noteworthy that since water has the highest specific heat capacity, the specific heat capacity of concrete increases slightly with the $\mathrm{W} / \mathrm{CM}$ ratio.

The variations of the heat generation per volume of concrete with the W/CM ratio at different PFA and CSF replacement ratios are shown in Fig. 2. This figure reveals that at a W/CM content between 0.24 to 0.40 (common $\mathrm{W} / \mathrm{CM}$ ratio range for normal- and high-strength concretes.), the heat generation decreased significantly as the increase in PFA replacement content or CSF replacement content. Such decrease in adiabatic heat generation indicates that during the first few days, the heat generated from the pozzolanic reaction of the PFA or CSF added was less than the heat generated from the hydration of the cement replaced. As explained before, the change in heat generation with increasing $\mathrm{W} / \mathrm{CM}$ ratio was the net effect of the increases in degree of hydration and degree of pozzolanic reaction and the decrease in cementitious materials content.

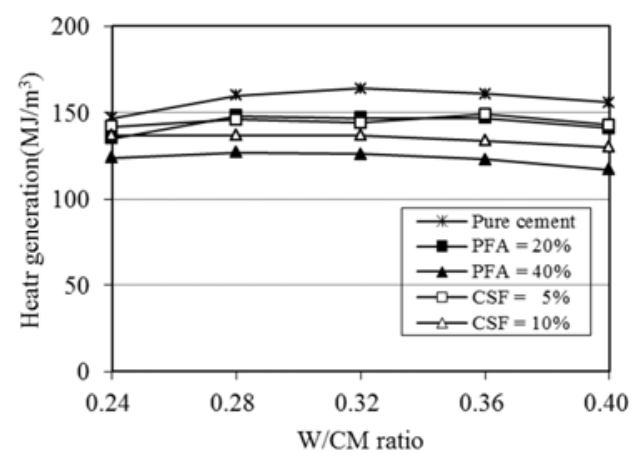

Figure 2. Results of total heat generation.

\subsection{Heat Generation Per Cementitious Materials}

The heat generation per weight of cementitious materials of each concrete mix was calculated by dividing the heat generation by the cementitious materials content and shown in Fig. 3. It is evident that in all cases, the heat generation per weight of cementitious materials decreased as the PFA or CSF replacement ratio increased. It is also evident that generally, the heat generation per weight of cementitious materials increased with the $\mathrm{W} / \mathrm{CM}$ ratio at a gradually decreasing rate. These increases of heat generation per cementitious materials content with increasing $\mathrm{W} / \mathrm{CM}$ ratio may be attributed to the effects of $\mathrm{W} / \mathrm{CM}$ ratio on the degree of hydration and degree of pozzolanic reaction. However, the effects of $\mathrm{W} / \mathrm{CM}$ ratio appeared to be less significant at higher CSF replacement ratio.

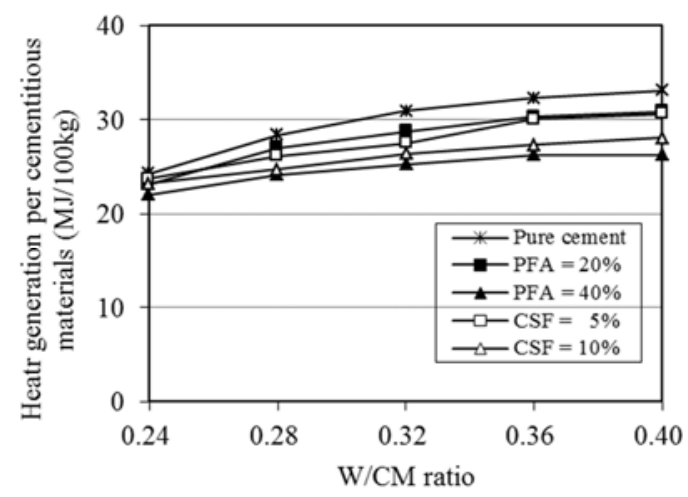

Figure 3. Results of total heat generation per cementitious materials. 


\subsection{Heat Generation at the Same Strength}

It is widely known that addition of PFA may decrease the strength while addition of CSF would significantly increase the strength. Hence, the effectiveness of concrete mix optimization in reducing heat generation should not be assessed on equal W/CM ratio basis but should rather be assessed on equal strength basis. Therefore, when designing a concrete mix for a given strength requirement, the W/CM ratio may be adjusted upwards to reduce the total cementitious materials content after CSF replacement.

To assess the heat generation on equal strength basis, the heat generations at different PFA and CSF replacement ratios are plotted against the 28-day cube strengths in Fig. 4. From each curve plotted, it is clear that at constant PFA and CSF replacement ratios, the heat generation increased only marginally with the strength. Comparing the different curves plotted, it is also obvious that on equal strength basis, CSF replacement was more effective than PFA replacement in reducing the heat generation.

Results clearly demonstrated that the heat generation is more influenced by the PFA and CSF replacement contents than the strength. Hence, depending on the PFA and CSF contents, a higher strength concrete does not necessarily generate more heat. If the higher strength is achieved by CSF replacement rath addition of CSF is much more effectively than addition of PFA in reducing heat generation er than by increasing the total cementitious materials content to reduce the $\mathrm{W} / \mathrm{CM}$ ratio, the higher strength concrete may even generate less heat.

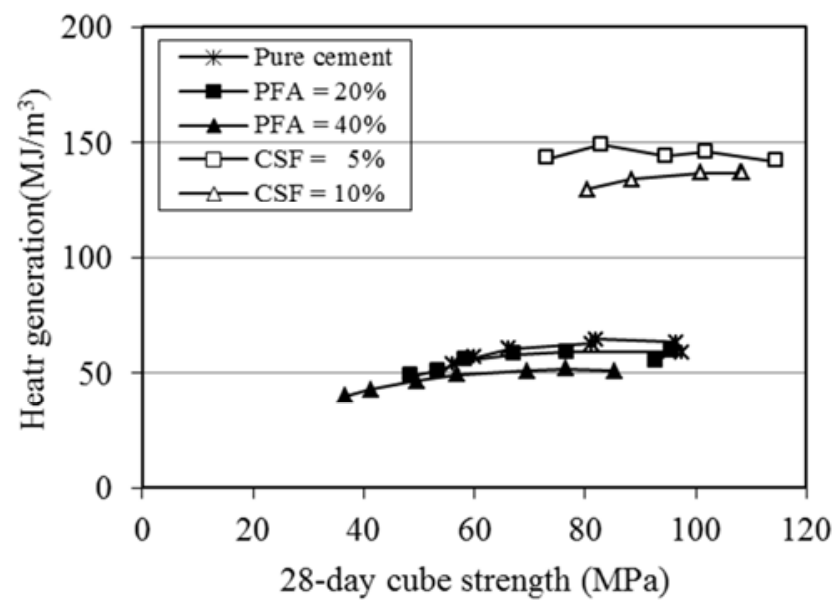

Figure 4. Results of total heat generation.

\section{Comparison of Effectiveness of PFA and CSF in Reducing Heat Generation}

The results in this study clearly showed that the addition of PFA or CSF as cement replacement could effectively reduce the heat generation of curing concrete. Generally, addition of $20 \%$ PFA is as effective as addition of 5\% CSF in heat reduction, while addition of $40 \%$ PFA would reduce more heat generation than addition of $10 \%$ CSF. Similarly, addition of $20 \%$ PFA and addition of $5 \%$ CSF would more or less the same reduce the heat generation per cementitious materials, while addition of $40 \%$ PFA would reduce more heat generation per cementitious materials than addition of $10 \%$ CSF. This is believed to due to the reason that the degree of pozzolanic reaction would decrease when the addition content of cementitious materials becomes high.

For the practical engineering use, the effectiveness of reduction in heat generation should be better assessed on equal strength basis than on equal W/CM ratio basis. In this regard, because addition of CSF would on one hand reduce the heat generation and on the other hand significantly increase the strength of concrete. Of course, the cost of CSF is much higher than the PFA and addition of CSF would significantly increase the required SP dosage to achieve the same workablility. To conclude, both the strategy of addition of PFA and addition of CSF could decrease the heat generation of curing concrete to alleviate the early thermal cracking, one shall comprehensively consider the effect of the addition of PFA/CSF on workability, strength and the cost of concrete when determining the strategy to reduce the heat generation.

\section{Conclusion}

An experimental program aiming to evaluate the effectiveness of PFA and CSF as cement replacement for reducing the heat generation of curing concrete has been completed. The major findings obtained in this study included:

1) addition of PFA or CSF as cement replacement could effectively reduce the adiabatic temperature rise and heat generation of curing concrete;

2) Addition of $20 \%$ PFA is as effective as addition of $5 \%$ CSF in heat reduction, while addition of $40 \%$ PFA would reduce more heat generation than addition of $10 \%$ CSF;

3) Addition of CSF is much more effectively than addition of PFA in reducing heat generation at the same strength.

\section{Acknowledgements}

The work described in this paper was supported by the grants Natural Science Foundation of Guangdong Province of China (Grant No. 2014A030310273 and Grant No. 2015A030310282), National Natural Science Foundation of China (Grant No. 51408144), 2016 Foshan Science and Technology Project (Project No. 2016AB000031) and Guangzhou Science (Technology) Research Project (Grant No. 201607010329).

\section{References}

[1] R. E. Davis, R. W. Carlson, J. W. Kelly, and H. E. Davis, "Properties of Cements and Concretes Containing Fly Ash," Journal of American Concrete Institute, vol. 33, No. 3, 1937, pp. 577-612. 
[2] P. B. Bamforth, "In Situ Measurement of the Effect of Partial Portland Cement Replacement Using either Fly Ash or Ground Granulated Blast-Furnace Slag on the Performance of Mass Concrete," Proceedings of the Institution of Civil Engineers, vol. 69, Part 2, 1980, pp. 777-800.

[3] M. I. Sanchez de Rojas, M. P. Luxan, M. Frias, and N. Garcia, "The Influence of Different Additions on Portland Cement Hydration Heat," Cement and Concrete Research, vol. 23, No. 1, 1993, pp. 46-54.

[4] A. Bilodeau, and vol. M. Malhotra, "Properties of High-Volume Fly Ash Concrete Made with High Early-Strength ASTM Type III Cement," ACI Special Publication SP-153, American Concrete Institute, USA, 1995, pp. 1-23.

[5] M. D. A. Thomas, P. K. Mukherjee, J. A. Sato, and M. F. Everitt, "Effect of Fly Ash Composition on Thermal Cracking in Concrete," ACI Special Publication SP-153, American Concrete Institute, USA, 1995, pp. 81-97.

[6] G. De Schutter, "Hydration and Temperature Development of Concrete Made with Blast-Furnace Slag Cement," Cement and Concrete Research, vol. 29, No. 1, 1999, pp. 143-149.

[7] J. Bai, and S. Wild, "Investigation of the Temperature Change and Heat Evolution of Mortar Incorporating PFA and Metakaolin," Cement and Concrete Composites, vol. 24, No. 2, 2002, pp. 201-209.

[8] C. D. Atis, "Heat Evolution of High-Volume Fly Ash Concrete," Cement and Concrete Research, vol. 32, No. 5, 2002, pp. 751-756.

[9] E. Sakai, S. Miyahara, S. Ohsawa, S. H. Lee and M. Daimon, "Hydration of Fly Ash Cement," Cement and Concrete Research, vol. 35, No. 6, 2005, pp. 1135-1140.

[10] D. G. Snelson, S. Wild, and M. O'Farrell, "Heat of Hydration of Portland Cement-Metakaolin-Fly Ash (PC-MK-PFA) Blends," Cement and Concrete Research, vol. 38, No. 6, 2008, pp. 832-840.

[11] I. Meland, "Influence of Condensed Silica Fume and Fly Ash on the Heat Evolution in Cement Pastes," ACI Special Publication SP-79, American Concrete Institute, USA, 1983, pp. 665-676.

[12] S. Lessard, P. C. Aitcin, and M. Regourd, "Development of a Low Heat of Hydration Blended Cement," ACI Special Publication SP-79, American Concrete Institute, USA, 1983, pp. 747-763.

[13] W. Kurdowski, and W. Nocun-Wczelik, "The Tricalcium Silicate Hydration in the Presence of Active Silica," Cement and Concrete Research, vol. 13, No. 3, 1983, pp. 341-348.

[14] A. Kumar, and D. M. Roy, "A Study of Silica-Fume Modified Cements of Varied Fineness," Journal of the American Ceramic Society, vol. 67, No. 1, 1984, pp. 61-64.

[15] C. Huang, and R. F. Feldman, "Hydration Reactions in Portland Cement-Silica Fume Blends," Cement and Concrete Research, vol. 15, No. 4, 1985, pp. 585-592.

[16] W. P. Ma, D. Sample, R. Martin, and P. W. Brown,
"Calorimetric Study of Cement Blends Containing Fly Ash, Silica Fume, and Slag at Elevated Temperatures," Cement, Concrete and Aggregate, vol. 16, No. 2, 1994, pp. 93-99.

[17] M. I. Sanchez de Rojas, and M. Frias, "The Influence of Silica Fume on the Heat of Hydration of Portland Cement," ACI Special Publication SP-153, American Concrete Institute, USA, 1995, pp. 829-843.

[18] A. M. Alshamsi, "Microsilica and Ground Granulated Blast Furnace Slag Effects on Hydration Temperature," Cement and Concrete Research, vol. 27, No. 12, 1997, pp. 1851-1859.

[19] D. P. Bentz, vol. Waller, and F. De Larrard, "Prediction of Adiabatic Temperature Rise in Conventional and High-Performance Concrete Using a 3-D Microstructural model," Cement and Concrete Research, vol. 28, No. 2, 1998, pp. 285-297.

[20] B. W. Langan, K. Weng, and M. A. Ward, "Effect of Silica Fume and Fly Ash on Heat of Hydration of Portland Cement," Cement and Concrete Research, vol. 32, No. 7, 2002, pp. 1045-1051.

[21] N. Y. Mostafa, and P. W. Brown, "Heat of Hydration of High Reactive Pozzolans in Blended Cements: Isothermal Conduction Calorimetry," Thermochimica Acta, vol. 435, No. 2, 2005, pp. 162-167.

[22] P. L. Ng, I. Y. T. Ng, and A. K. H. Kwan, "Heat Loss Compensation in Semi-Adiabatic Curing Test of Concrete," ACI Materials Journal, vol. 105, No. 1, 2008, pp. 52-61.

[23] E. H. Kadri, and R. Duval, "Hydration Heat Kinetics of Concrete with Silica Fume," Construction and Building Materials, vol. 23, No. 11, 2009, pp. 3388-3392.

[24] ACI Committee 234. Guide for the Use of Silica Fume in Concrete, American Concrete Institute, USA, 2006.

[25] I. Y. T. Ng, P. L. Ng and A. K. H Kwan, "Effects of Cement and Water Contents on Adiabatic Temperature Rise of Concrete," ACI Materials Journal, vol. 106, No. 1, 2009, pp. 42-49.

[26] G. De Schutter, and L. Taerwe, "Specific Heat and Thermal Diffusivity of Hardening Concrete," Magazine of Concrete Research, vol. 47, No. 172, 1995, pp. 203-208.

[27] K. Van Breugel, Simulation of Hydration and Formation of Structure in Hardening Cement-Based Materials, PhD Thesis, Delft University of Technology, Delft, The Netherlands, 1991, $295 \mathrm{pp}$.

[28] F. De Larrard, Concrete Mixture Proportioning: A Scientific Approach, E \& FN Spon, New York, 1999, Chapter 2, pp. 77-221.

[29] S. Krishnaiah, and D. N. Singh, "Determination of Thermal Properties of Some Supplementary Cementing Materials Used in Cement and Concrete," Construction and Building Materials, vol. 20, No. 3, 2006, pp. 193-198.

[30] J. P. Holman, Heat Transfer, 10th Edition, McGraw Hill, New York, USA, 2010, Appendix A.

[31] D. R. Lide, CRC Handbook of Chemistry and Physics, 91st Edition, CRC LLC, USA, 2010. 